\title{
n-Nonane hydroisomerization over hierarchical SAPO-11-based catalysts with sodium dodecylbenzene sulfonate as a dispersant
}

\author{
Cheng-Long Wen ${ }^{1} \cdot$ Jun-Dong Xu ${ }^{1} \cdot$ Xue-Man Wang $^{1} \cdot$ Yu Fan $^{1}$
}

Received: 19 May 2020 / Accepted: 2 October 2020 / Published online: 13 February 2021

(c) The Author(s) 2021

\begin{abstract}
To enhance the gasoline octane number, low-octane linear n-alkanes should be converted into their high-octane di-branched isomers via n-alkane hydroisomerization. Therefore, hierarchical SAPO-11-based catalysts are prepared by adding different contents of sodium dodecylbenzene sulfonate (SDBS), and they are applied in $n$-nonane hydroisomerization. When $n(\mathrm{SDBS}) / n\left(\mathrm{SiO}_{2}\right)$ is less than or equal to 0.125 , the synthesized hierarchical molecular sieves are all pure SAPO-11, and as the SDBS content increases, the submicron particle size decreases, and the external surface area (ESA) increases. Additionally, these hierarchical SAPO-11 have smaller submicron particles and higher ESA values than conventional SAPO11 . When $n(\mathrm{SDBS}) / n\left(\mathrm{SiO}_{2}\right)$ is greater than 0.125 , with increasing SDBS content $\left(n(\mathrm{SDBS}) / n\left(\mathrm{SiO}_{2}\right)=0.25\right)$, the synthesized SAPO-11 contains amorphous materials, which leads to a decline in the ESA; with the further increase in SDBS content $\left(n(\mathrm{SDBS}) / n\left(\mathrm{SiO}_{2}\right)=0.5\right)$, the products are all amorphous materials. These results indicate that in the case of $n(\mathrm{SDBS}) / n\left(\mathrm{SiO}_{2}\right)=0.125$, the synthesized SAPO-11 molecular sieve $\left(\mathrm{S}_{-} \mathrm{S}_{3}\right)$ has the most external Brønsted acid centers and the highest ESA of these SAPO-11, and these advantages favor generation of the di-branched isomers in hydrocarbon hydroisomerization. Among these Pt/SAPO-11 catalysts, $\mathrm{Pt} / \mathrm{S}-\mathrm{S}_{3}$ displays the highest selectivity to entire isomers (83.4\%), the highest selectivity to di-branched isomers $(28.1 \%)$ and the minimum hydrocracking selectivity (15.7\%) in $n$-nonane hydroisomerization.
\end{abstract}

Keywords SAPO-11 molecular sieve $\cdot n$-Nonane hydroisomerization $\cdot$ External surface area $\cdot$ External Brønsted acid centers $\cdot$ Selectivity to di-branched isomers

\section{Introduction}

Hydroisomerization is a technique to convert linear $n$-alkanes to their isomers, and it is a crucial component of the petroleum processing industry (Jin et al. 2009; Qin et al. 2011; Chi et al. 2013; Wen et al. 2017; Güleç et al. 2019; Jaroszewska et al. 2019). The hydroisomerization of $n$-alkanes can improve the quality of oil, such as decreasing the diesel pour point, enhancing the lubricant cold flow property and increasing the octane number of gasoline (Gomes et al. 2017; Belinskaya et al. 2019). Di-branched

\section{Edited by Xiu-Qiu Peng}

Yu Fan

fanyu@cup.edu.cn

1 State Key Laboratory of Heavy Oil Processing, China University of Petroleum, Beijing 102249, People's Republic of China alkane isomers have high-octane numbers, and thus, increasing the number of di-branched alkane isomers during hydroisomerization can effectively enhance the octane number of gasoline (Fan et al. 2012; Guo et al. 2013).

Silicoalminophosphate-11 (SAPO-11) is a microporous molecular sieve with an elliptical ten-membered ring channel structure $(3.9 \times 6.3 \AA)$ and possesses mild acidity (Guo et al. 2012; Song et al. 2012). SAPO-11 is extensively used in long-chain $n$-alkane hydroisomerization, and it is considered a good support for hydroisomerization (Fan et al. 2012; Yang et al. 2019a). However, conventional SAPO-11 has large submicron particles and a small external surface area (ESA), and it shows a good selectivity to mono-branched isomers but a poor selectivity to di-branched isomers in long-chain $n$-alkane hydroisomerization (Höchtl et al. 2001; Chen et al. 2017). Compared with mono-branched isomers, di-branched isomers with higher octane numbers can efficiently improve the gasoline quality (Chica and Corma 1999; Zhang et al. 2017; Han et al. 2020). The diameter of the 
di-branched isomers, such as 2,6-dimethylheptane (7.1 $\AA$ ), is larger than the pore openings of SAPO-11 (6.3 $\AA$ ) (Akhmedov and Al-Khowaiter 2007). As a result, the di-branched isomers fail to be produced inside the pores of SAPO-11. According to "pore mouth" theory (Taylor and Petty 1994), the di-branched isomers are generated on Brønsted acid centers (BAC), which are situated on the external surface (ES) of SAPO-11. Therefore, SAPO-11 with a high ESA provides more active sites for the generation of the di-branched alkane isomers, thereby enhancing the selectivity to di-branched isomers during hydroisomerization.

The synthesis of SAPO-11 with a high ESA has attracted substantial attention. Yang reported a seed-induced steamassisted method to synthesize mesoporous SAPO-11 using cetyltrimethylammonium bromide and F127 as the templates (Yang et al. 2019b). Sheng reported that mesoporous SAPO-11 with a high ESA was synthesized via a solventfree method (Sheng et al. 2019). Kim reported a method to obtain mesoporous SAPO-11 using carbon materials as the templates (Kim et al. 2014). Liu et al. reported a method to synthesize hierarchical SAPO-11 by adding glucose (Liu et al. 2015). The above methods slightly enhance the ESA of SAPO-11. A new method to synthesize SAPO-11 with a higher ESA should be proposed. Anionic surfactants are widely used in the preparation of mesoporous silica materials, the preparation of highly dispersed catalysts and the preparation of active carbon with a high capacity of heavy metal ions (Che et al. 2003; Ahn et al. 2009; Huang et al. 2018). To date, the synthesis of hierarchical silicoalminophosphate molecular sieves using anionic surfactants as dispersants has not been reported.

Herein, hierarchical SAPO-11 was synthesized via adding various amounts of sodium dodecylbenzene sulfonate (SDBS). The properties of these hierarchical samples were characterized. The $n$-nonane hydroisomerization performance of these samples was investigated. The hierarchical SAPO- 11 synthesized at $n(\mathrm{SDBS}) / n\left(\mathrm{SiO}_{2}\right)=0.125$ has more external Brønsted acid centers (EBAC) and a higher ESA than conventional SAPO-11 and other counterparts. The prepared Pt/SAPO-11 catalyst shows a higher isomer selectivity and a lower hydrocracking selectivity in the hydroisomerization of $n$-nonane.

\section{Experimental}

\subsection{Materials}

Pseudoboehmite (73.0 wt $\%, \mathrm{Al}_{2} \mathrm{O}_{3}$ ) was purchased from Tianjin-Hengmeilin company. Di- $n$-propylamine (99.5 wt $\%, \mathrm{C}_{6} \mathrm{H}_{15} \mathrm{~N}$, DPA), chloroplatinic acid (37.0 wt $\%$, $\left.\mathrm{H}_{2} \mathrm{PtCl}_{6}\right)$, phosphoric acid $\left(85.0 \mathrm{wt} \%, \mathrm{H}_{3} \mathrm{PO}_{4}\right)$, sodium dodecylbenzene sulfonate ( $\mathrm{SDBS}, \mathrm{C}_{18} \mathrm{H}_{29} \mathrm{NaO}_{3} \mathrm{~S}$, 95.0 wt $\%$ ), tetraethoxysilane (99.0 wt $\%, \mathrm{C}_{8} \mathrm{H}_{20} \mathrm{O}_{4} \mathrm{Si}$, TEOS) and $n$-nonane $\left(\mathrm{C}_{9} \mathrm{H}_{20}, 98.0 \mathrm{wt} \%\right)$ were supplied by Aladdin. All of the reagents were adopted without further purification.

\subsection{Synthesis of SAPO-11}

\subsubsection{Synthesis of conventional SAPO-11}

Conventional SAPO-11 was synthesized in accordance with a procedure described in the literature (Wen et al. 2017, 2019). The obtained gel was composed of 0.4 TEOS: 0.95 $\mathrm{P}_{2} \mathrm{O}_{5}: 1.2$ DPA: $1.0 \mathrm{Al}_{2} \mathrm{O}_{3}: 40 \mathrm{H}_{2} \mathrm{O}$, and it was placed into a $100 \mathrm{~mL}$ reactor and then treated at $473 \mathrm{~K}$ for $24 \mathrm{~h}$. The final product was produced by water washing, drying and calcining at $873 \mathrm{~K}$ for $6 \mathrm{~h}$, and it was named S-C.

\subsubsection{Synthesis of hierarchical SAPO-11}

First, $12.2 \mathrm{~g}$ of $\mathrm{H}_{3} \mathrm{PO}_{4}$ was added to $40.0 \mathrm{~g}$ of water. Afterward, $8.1 \mathrm{~g}$ of PB, $4.7 \mathrm{~g}$ of TEOS and $6.8 \mathrm{~g}$ of DPA were mixed with the solution in sequence under stirring for $6 \mathrm{~h}$. Finally, different amounts of SDBS were added to the suspension, and it was stirred for $1 \mathrm{~h}$. The final gel had a composition of 0.4 TEOS: $0.95 \mathrm{P}_{2} \mathrm{O}_{5}: 1.2$ DPA: $1.0 \mathrm{Al}_{2} \mathrm{O}_{3}: x$ SDBS: $40 \mathrm{H}_{2} \mathrm{O}(x=0.01,0.025,0.05,0.1$ and 0.2 , respectively), and then it was placed into a $100 \mathrm{~mL}$ reactor and treated at $473 \mathrm{~K}$ for $24 \mathrm{~h}$. The series of hierarchical SAPO11 were obtained by water washing, drying and calcining at $873 \mathrm{~K}$ for $6 \mathrm{~h}$. These obtained hierarchical SAPO-11 were labeled $\mathrm{S}-\mathrm{S}_{x}(x=1,2,3,4$ and 5), and they are collectively named $\mathrm{S}-\mathrm{S}_{x}$.

\subsection{Preparation of catalysts}

The Pt/SAPO-11 catalysts were prepared with the Pt loadings of $0.5 \mathrm{wt} \%$. First, $\mathrm{S}-\mathrm{C}, \mathrm{S}-\mathrm{S}_{1}, \mathrm{~S}-\mathrm{S}_{2}$ and $\mathrm{S}-\mathrm{S}_{3}$ were pressed into tablets and sieved to $20-40$ mesh. Afterward, these samples were impregnated with $\mathrm{H}_{2} \mathrm{PtCl}_{6}$ solutions, and then they were dried and calcined at $723 \mathrm{~K}$ for $4 \mathrm{~h}$. Finally, these catalysts were labeled $\mathrm{Pt} / \mathrm{S}-\mathrm{C}, \mathrm{Pt} / \mathrm{S}-\mathrm{S}_{1}, \mathrm{Pt} / \mathrm{S}-\mathrm{S}_{2}$ and $\mathrm{Pt} / \mathrm{S}-\mathrm{S}_{3}$, respectively.

\subsection{Characterization}

$\mathrm{X}$-ray diffraction (XRD) analyses were employed on a D8 ADVANCE apparatus with a rate of $4 \% \mathrm{~min}$ and a range from $5^{\circ}$ to $50^{\circ}$. A HITACHI SU8010 scanning electron microscope (SEM) was used to measure the particle sizes and morphologies of samples. The pore properties of samples were obtained by the nitrogen adsorption-desorption analysis using an ASAP 2010 instrument. First, $0.1 \mathrm{~g}$ of the sample was heated at $673 \mathrm{~K}$ for $3 \mathrm{~h}$ under vacuum and followed by the physical adsorption measurement using nitrogen as the adsorbate at 
$77 \mathrm{~K}$. The BET surface area (BSA) and ESA of these samples were obtained by the Brunauer-Emmett-Teller method and the t-plot method, respectively. The pyridine infrared (Py-IR) measurement was performed to obtain the acidic properties of all samples using a NICOLET-750 infrared spectrometer. A sample disk with a diameter of $12 \mathrm{~mm}$ and a mass of $20 \mathrm{mg}$ was treated under vacuum at $673 \mathrm{~K}$. Afterward, the adsorption of pyridine on the disk was performed for $0.25 \mathrm{~h}$, and the spectra were recorded at room temperature after the Py desorption at 473 and $573 \mathrm{~K}$, respectively. The number of EBAC on all samples was determined by means of a 2,6-dimethylpyridine adsorption infrared (2,6-DMPy-IR) experiment, and its measurement steps were in accordance with those of the Py-IR experiment. After the desorption of 2,6-dimethylpyridine at 473 and $573 \mathrm{~K}$, respectively, the spectra were obtained at room temperature. The adsorption instrument of Auto Chem II 2920 was used to measure the Pt dispersions of all samples. The calculation methods of pore volume, acid amounts and $\mathrm{Pt}$ dispersion were presented in the supplementary information.

\subsection{Catalyst assessment}

The hydroisomerization of $n$-nonane on these prepared catalysts was investigated in a microreactor. $2.0 \mathrm{~mL}$ of quartz was blended with the catalyst $(2.0 \mathrm{~mL})$, and the mixture was loaded in the microreactor. The reduction of catalysts was performed at a pressure of $1.5 \mathrm{MPa}$ and a temperature of $673 \mathrm{~K}^{\text {in } \mathrm{H}_{2}}$ for $4 \mathrm{~h}$. Afterward, $n$-nonane hydroisomerization over these catalysts was performed at $613 \mathrm{~K}$, a $v\left(\mathrm{H}_{2}\right) / v(n$-nonane) of 400 , a pressure of $1.5 \mathrm{MPa}$ and different weight hourly space velocities (WHSVs).

The products of $n$-nonane hydroisomerization were determined by an SP 3420 gas chromatograph instrument, which has an HP-PONA column $(50 \mathrm{~m} \times 0.25 \mathrm{~mm})$ and a flame ionization detector. The hydroisomerization conversion of $n$-nonane (Conversion), the selectivity to entire isomers $\left(S_{\mathrm{E}}\right)$, the selectivity to di-branched isomers $\left(S_{\mathrm{DB}}\right)$ and the hydrocracking selectivity $\left(S_{\mathrm{H}}\right)$ were calculated by the following formulas:

$$
\begin{aligned}
& \text { Conversion }=\frac{C_{\mathrm{f}}-C_{\mathrm{p}}}{C_{\mathrm{f}}} \times 100 \% \\
& S_{\mathrm{E}}=\frac{C_{\mathrm{E}}}{C_{\mathrm{f}}-C_{\mathrm{p}}} \times 100 \% \\
& S_{\mathrm{DB}}=\frac{C_{\mathrm{DB}}}{C_{\mathrm{f}}-C_{\mathrm{p}}} \times 100 \% \\
& S_{\mathrm{H}}=\frac{C_{\mathrm{H}}}{C_{\mathrm{f}}-C_{\mathrm{p}}} \times 100 \%
\end{aligned}
$$

where $C_{\mathrm{f}}, C_{\mathrm{p}}, C_{\mathrm{H}}, C_{\mathrm{E}}$ and $C_{\mathrm{DB}}$ are the n-nonane concentration in the feedstock and the concentrations of $n$-nonane, hydrocracking products, entire isomers and di-branched isomers in the products, respectively.

The hydroisomerization of $n$-nonane was expected to be a pseudo-first-order reaction. The following formula was used to calculate its rate constant ( $k$ ) (Campelo et al. 1995).

$k=\frac{F}{q} \ln \left(\frac{1}{1-c}\right)$

In the formula, $F, q$ and $c$ are the $n$-nonane feed rate (mol $\mathrm{s}^{-1}$ ), the mass of the catalyst ( $\mathrm{g}$ ) and the $n$-nonane conversion, respectively.

The following formula was used to calculate the value of the turnover frequency (TOF) for the catalyst (Guo et al. 2013):

$\mathrm{TOF}=\frac{n}{C_{\mathrm{B}}}$

where $C_{\mathrm{B}}$ and $n$ are the number of medium and strong BAC (MSBAC) per gram of catalyst $\left(\mathrm{mol} \mathrm{g}^{-1}\right)$ and the number of reacted $n$-nonane per second per gram of the catalyst (mol $\left.\mathrm{g}^{-1} \mathrm{~s}^{-1}\right)$, respectively.

\section{Results and discussion}

\subsection{XRD}

The XRD spectra of the uncalcined $\mathrm{S}-\mathrm{S}_{x}(x=1,2,3,4$ and $5)$ and $\mathrm{S}-\mathrm{C}$ molecular sieves are shown in Fig. 1. The relative crystallinities of $\mathrm{S}-\mathrm{S}_{x}(x=1,2,3,4$ and 5) and $\mathrm{S}-\mathrm{C}$ are $98.4 \%, 97.6 \%, 97.1 \%, 32.5 \%, 0 \%$ and $100 \%$, respectively (Table S1). S-S $(x=1,2,3$ and 4$)$ and S-C present characteristic peaks assigned to SAPO-11 (Zhao et al. 2014; Lyu et al. 2019). S- $S_{4}$ shows characteristic peaks with a lower intensity than S-C and S-S $\mathrm{S}_{x}(x=1,2$ and 3), indicating the lower crystallinity of $\mathrm{S}_{-} \mathrm{S}_{4}(32.5 \%)$. S $-\mathrm{S}_{5}$ does not show characteristic peaks attributed to SAPO-11, indicating that SAPO-11 fails to be synthesized. The above results show that when $n$ (SDBS) $/ n\left(\mathrm{SiO}_{2}\right)$ is less than or equal to 0.125 , SAPO-11 molecular sieves are successfully synthesized; when $n(\mathrm{SDBS}) / n\left(\mathrm{SiO}_{2}\right)$ is greater than 0.125 , as the SDBS content increases $\left(n(\mathrm{SDBS}) / n\left(\mathrm{SiO}_{2}\right)=0.25\right)$, the synthesized SAPO-11 molecular sieve presents a lower crystallinity; with a further increase in the SDBS content $\left(n(\mathrm{SDBS}) / n\left(\mathrm{SiO}_{2}\right)=0.5\right)$, amorphous materials are obtained without the SAPO-11 molecular sieve. 


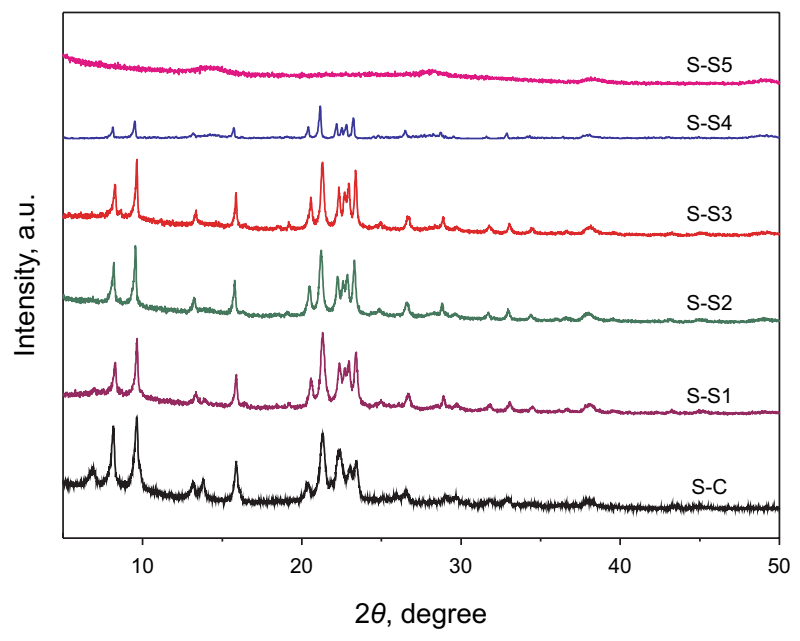

Fig. 1 XRD spectra of the uncalcined $\mathrm{S}-\mathrm{C}$ and $\mathrm{S}-\mathrm{S}_{x}(x=1,2,3,4$ and 5) molecular sieve

\subsection{SEM}

The SEM pictures of S-C (a) and S-S $\mathrm{S}_{x}(x=1,2,3,4$ and 5) (b-f) are displayed in Fig. 2. S-C and $\mathrm{S}-\mathrm{S}_{x}(x=1,2$ and 3) present spherical particles, which are composed of many small SAPO-11 submicron particles. The submicron particle sizes of $\mathrm{S}-\mathrm{C}, \mathrm{S}-\mathrm{S}_{1}, \mathrm{~S}-\mathrm{S}_{2}$ and $\mathrm{S}-\mathrm{S}_{3}$ are $500,300,250$ and $110 \mathrm{~nm}$, respectively. $\mathrm{S}-\mathrm{S}_{5}$ shows irregular polyhedral particles (Fig. 2f), and according to the XRD results, they are amorphous materials. $\mathrm{S}_{-} \mathrm{S}_{4}$ has both spherical particles of SAPO-11 (marked with squares) and irregular polyhedral particles (marked with circles) (Fig. 2e), which is the same morphology as that of $\mathrm{S}_{-} \mathrm{S}_{5}$ (Fig. 2f). Therefore, the irregular polyhedral particles of $\mathrm{S}-\mathrm{S}_{4}$ are amorphous materials. Compared with S-C, S-S $(x=1,2$ and 3$)$ molecular sieves possess smaller submicron particles, and as the SDBS content increases, the submicron particle sizes of $\mathrm{S}-\mathrm{S}_{1}, \mathrm{~S}-\mathrm{S}_{2}$ and $\mathrm{S}_{-} \mathrm{S}_{3}$ gradually decrease. With a further increase in the SDBS content, $\mathrm{S}_{-} \mathrm{S}_{4}$ develops an amorphous component, and $\mathrm{S}-\mathrm{S}_{5}$ becomes completely amorphous.

The synthesis principles of $\mathrm{S}-\mathrm{C}$ and $\mathrm{S}-\mathrm{S}_{x}$ molecular sieves are presented in Fig. 3. During synthesis, molecular sieve precursors are first generated, and then they polymerize to form the molecular sieve crystal nuclei; finally, the molecular sieve is obtained via the growth of these crystal nuclei (Cundy and Cox 2005; Ikuno et al. 2015). The critical micelle concentration $(\mathrm{cmc})$ of SDBS is $3.0 \mathrm{mmol} \mathrm{L}^{-1}$ at $308 \mathrm{~K}$, and as the temperature increases by $5 \mathrm{~K}$, it increases by ca. $0.1 \mathrm{mmol} \mathrm{L}^{-1}$ (Hait et al. 2003). During the syntheses of $S-S_{1}, S-S_{2}$, $\mathrm{S}-\mathrm{S}_{3}, \mathrm{~S}-\mathrm{S}_{4}$ and $\mathrm{S}-\mathrm{S}_{5}$, the concentrations of SDBS are $14.0,34.9,69.9,139.7$ and $279.4 \mathrm{mmol} \mathrm{L}^{-1}$, respectively, which are much higher than the cmc of SDBS. Therefore, the micelles of $\mathrm{DBS}^{-}$can be formed during the synthesis of these hierarchical samples, and they play a role in dispersing the reactants and the molecular sieve precursors and inhibiting the growth of the molecular sieve (Sakthivel et al. 2009; Wang et al. 2012). During the synthesis of S-C, large SAPO-11 submicron particles are easily obtained by the polymerization and growth of the SAPO11 crystal nuclei because the SAPO-11 crystal nuclei show poor dispersion in the absence of SDBS (Fig. 3a). During the synthesis of molecular sieves, addition of an anionic surfactant can shorten the molecular sieve nucleation period (Myatt et al. 1994). Thus, $\mathrm{S}-\mathrm{S}_{x}(x=1,2$ and 3 ) with small submicron particles is obtained due to the addition of SDBS to the synthetic raw materials, which shortens the SAPO-11 nucleation period and results in production of more SAPO-11 crystal nuclei. Therefore, $\mathrm{S}-\mathrm{S}_{x}(x=1,2$ and 3$)$ molecular sieves have smaller submicron particles than S-C. SAPO-11 is one of the silicoalminophosphate molecular sieves, and it possesses negative charges due to the substitution of $\mathrm{Si}$ in the neutral $\mathrm{AlPO}_{4}$ framework (Jahn et al. 1990). The low SDBS content leads to a minimum number of $\mathrm{DBS}^{-}$micelles, and it is difficult to achieve a good dispersion of the SAPO-11 precursors. In addition, the SAPO-11 crystal nuclei are poorly dispersed because of their weak electrostatic repulsive interaction with the $\mathrm{DBS}^{-}$micelles during the nucleation process. Thus, the obtained SAPO11 has relatively large submicron particles (Fig. 3b). As the SDBS content increases, more $\mathrm{DBS}^{-}$micelles are formed, and they better disperse the SAPO-11 precursors. Furthermore, during the nucleation process, the electrostatic repulsive interaction between the SAPO-11 crystal nuclei and the $\mathrm{DBS}^{-}$micelles increases, resulting in a better dispersion of the SAPO-11 crystal nuclei. The $\mathrm{DBS}^{-}$micelles as a hydrophobic layer cut off the supply of active reactants to SAPO-11 submicron particles, thereby limiting the growth of the SAPO-11 submicron particles. Consequently, the SAPO-11 submicron particle size decreases (Fig. 3c). When $n(\mathrm{SDBS}) / n\left(\mathrm{SiO}_{2}\right)$ is greater than 0.125 , as the SDBS content increases $\left(n(\mathrm{SDBS}) / n\left(\mathrm{SiO}_{2}\right)=0.25\right)$, extensive $\mathrm{DBS}^{-}$micelles are formed, which leads to excessive dispersion of some SAPO-11 precursors and makes these precursors difficult to polymerize, thereby preventing the Formation of SAPO-11 crystal nuclei. As a consequence, the synthesized SAPO-11 contains amorphous materials, and thus, it exhibits a low crystallinity (Fig. 3d). With a further increase in the SDBS content $\left(n(\mathrm{SDBS}) / n\left(\mathrm{SiO}_{2}\right)=0.5\right)$, the number of DBS micelles continues to increase, which makes all the SAPO-11 precursors excessively dispersed, leading to a failure to nucleate. As a result, the products are all amorphous materials (Fig. 3e). The amorphous materials decrease the amount of BAC (Li et al. 2013), the crystallinity and the BSA of the molecular sieves 

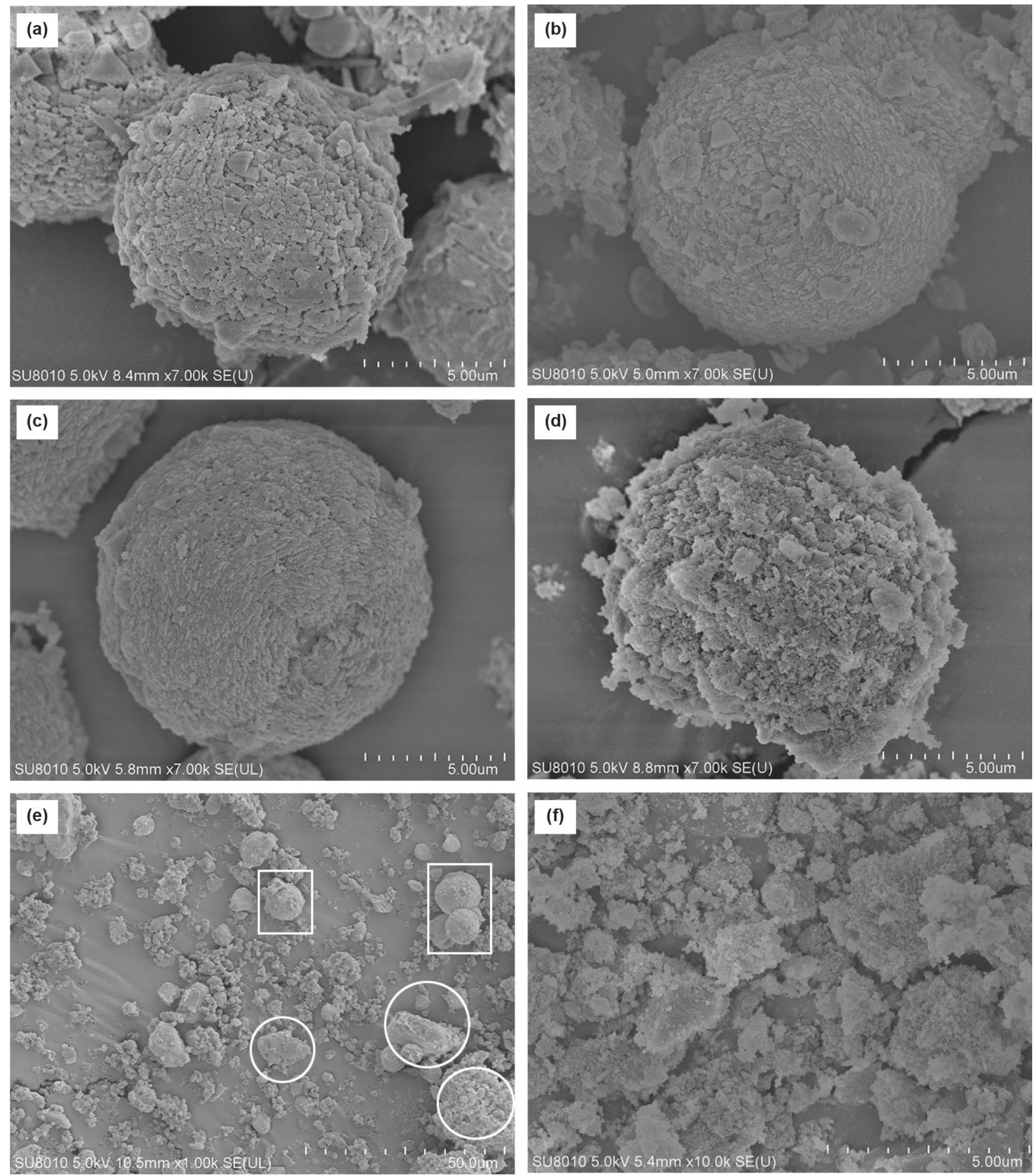

Fig. 2 SEM pictures of S-C (a), S-S $\mathrm{S}_{1}(\mathbf{b}), \mathrm{S}-\mathrm{S}_{2}(\mathbf{c}), \mathrm{S}-\mathrm{S}_{3}(\mathbf{d}), \mathrm{S}-\mathrm{S}_{4}(\mathbf{e})$ and $\mathrm{S}-\mathrm{S}_{5}(\mathbf{f})$

(Chen et al. 2013), thus disfavoring hydrocarbon hydroisomerization (Kuchar et al. 1993). Considering that $\mathrm{S}_{-} \mathrm{S}_{4}$ with a low crystallinity contains amorphous materials and $\mathrm{S}-\mathrm{S}_{5}$ is completely amorphous, $\mathrm{S}-\mathrm{C}, \mathrm{S}-\mathrm{S}_{1}, \mathrm{~S}-\mathrm{S}_{2}$ and $\mathrm{S}-\mathrm{S}_{3}$ are selected for further study.

\subsection{Nitrogen adsorption-desorption}

The nitrogen adsorption-desorption isotherms of $\mathrm{S}-\mathrm{S}_{x}$ $(x=1,2,3$ and 4$)$ and S-C are shown in Fig. 4, and they are classified as type IV isotherms. $\mathrm{S}-\mathrm{S}_{x}(x=1,2,3$ and 4$)$ and 


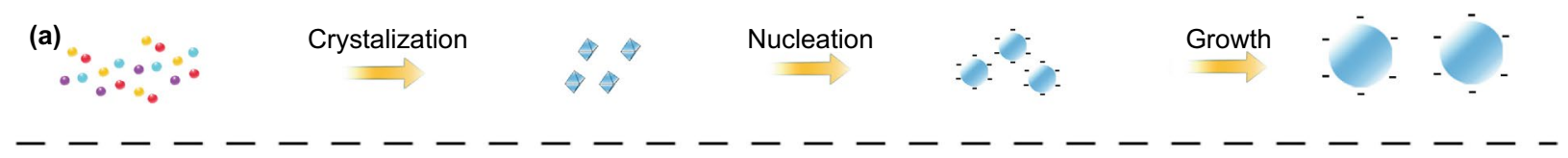

(b)

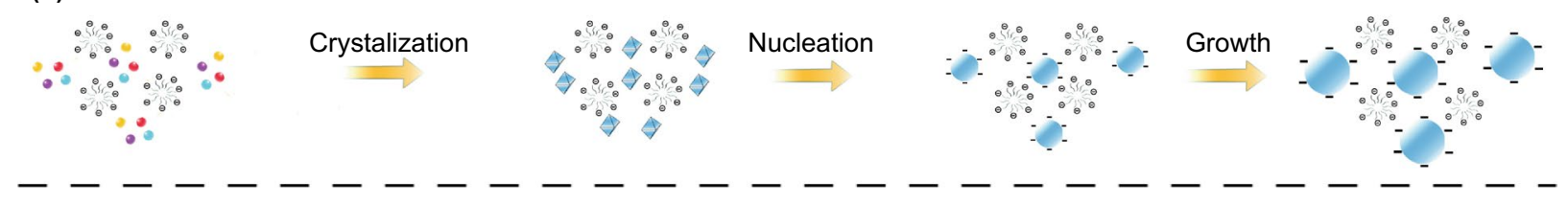

(c)
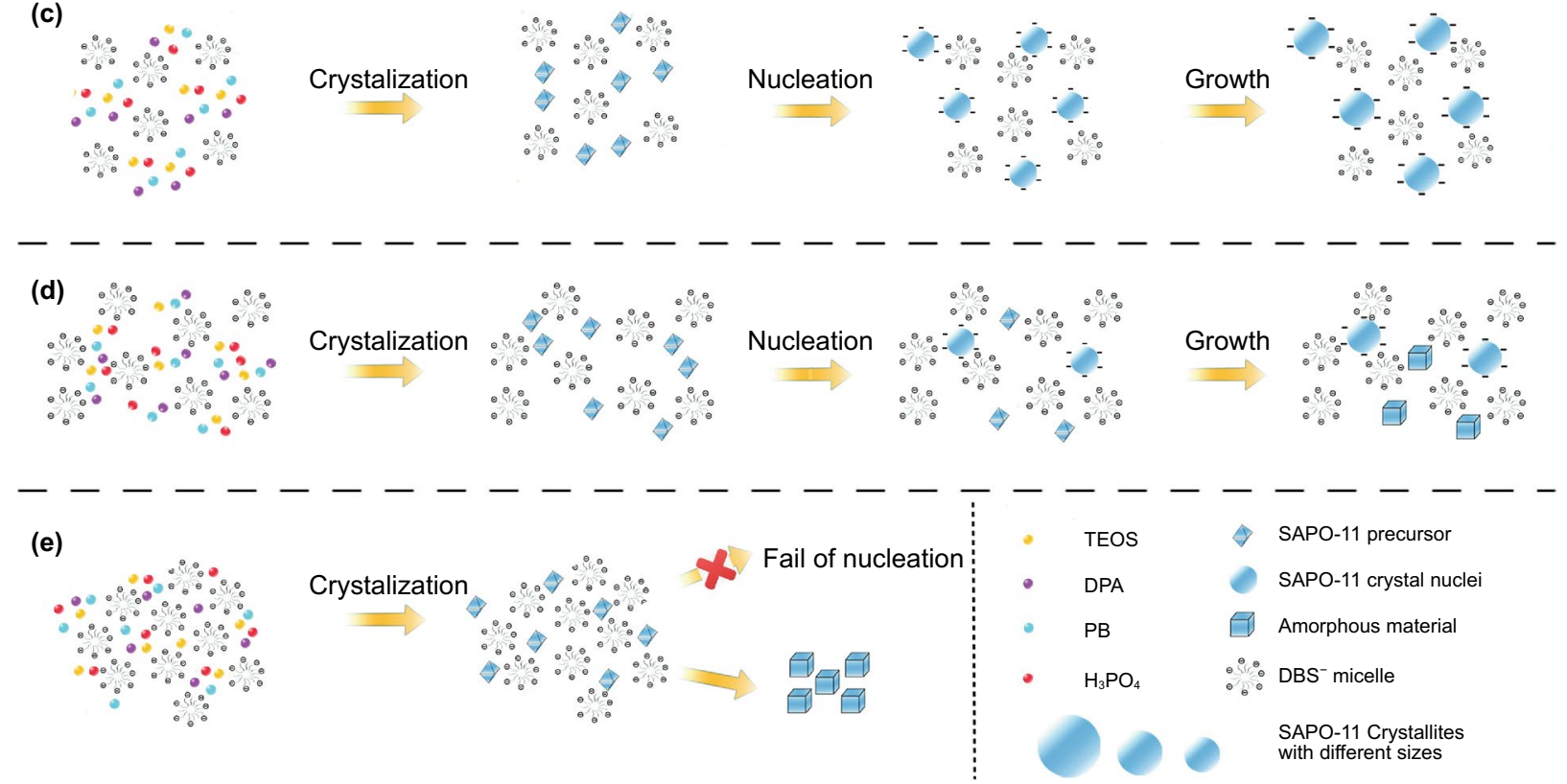

Fig. 3 Schematic diagram of the synthesis principles of $\mathrm{S}-\mathrm{C}(\mathbf{a}), \mathrm{S}-\mathrm{S}_{1}$ and $\mathrm{S}-\mathrm{S}_{2}(\mathbf{b}), \mathrm{S}-\mathrm{S}_{3}(\mathbf{c}), \mathrm{S}-\mathrm{S}_{4}(\mathbf{d})$ and $\mathrm{S}-\mathrm{S}_{5}(\mathbf{e})$

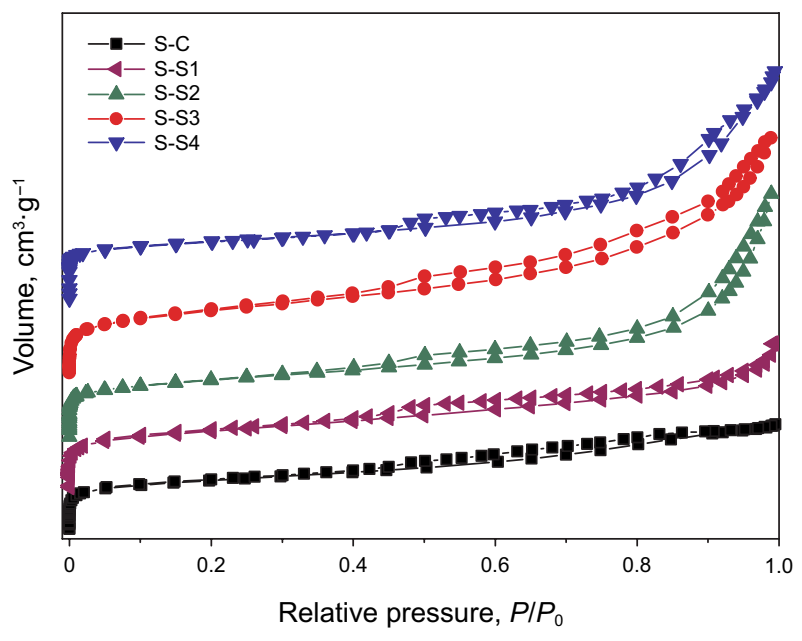

Fig. $4 \mathrm{~N}_{2}$ adsorption-desorption isotherms of $\mathrm{S}-\mathrm{C}$ and $\mathrm{S}-\mathrm{S}_{x}(x=1,2$, 3 and 4)
S-C display both the characteristic of microporous materials at a low relative pressure $\left(P / P_{0}<0.001\right)$ and the type $\mathrm{H} 3$ hysteresis loops at a high relative pressure $\left(P / P_{0}=0.50-0.96\right)$. The pore distributions of $\mathrm{S}-\mathrm{S}_{x}(x=1,2,3$ and 4$)$ and $\mathrm{S}-\mathrm{C}$ are displayed in Fig. 5. S-S $(x=1,2,3$ and 4$)$ and $\mathrm{S}-\mathrm{C}$ show peaks at $3.8 \mathrm{~nm}$ because of the tensile strength effect (Danilina et al. 2010; Sun et al. 2020). S-S $, S-S_{2}, S-S_{3}$ and $\mathrm{S}-\mathrm{S}_{4}$ present peaks at $15,15,10$ and 30,15 and $20 \mathrm{~nm}$, respectively. The results indicate that there are mesopores in $\mathrm{S}-\mathrm{S}_{x}(x=1,2,3$ and 4$)$. $\mathrm{S}-\mathrm{C}$ shows a broad peak with a very low intensity at $9-30 \mathrm{~nm}$, and it indicates that there is an extremely small number of mesopores in $\mathrm{S}-\mathrm{C}$.

The texture properties of $\mathrm{S}-\mathrm{C}, \mathrm{S}-\mathrm{S}_{1}, \mathrm{~S}-\mathrm{S}_{2}, \mathrm{~S}-\mathrm{S}_{3}$ and $\mathrm{S}-\mathrm{S}_{4}$ are presented in Table 1. The BSA and ESA of $\mathrm{S}-\mathrm{C}, \mathrm{S}-\mathrm{S}_{1}, \mathrm{~S}-\mathrm{S}_{2}, \mathrm{~S}-\mathrm{S}_{3}$ and $\mathrm{S}-\mathrm{S}_{4}$ are 221 and 80 , 243 and 117,257 and 132, 275 and 165, 203 and 111 $\mathrm{m}^{2} \mathrm{~g}^{-1}$, respectively. The ESA and mesoporous volume of $\mathrm{S}_{-} \mathrm{S}_{x}(x=1,2$ and 3$)$ molecular sieves are larger than those of $\mathrm{S}-\mathrm{C}$, owing to the smaller submicron particles and greater number of mesopores. As the SDBS 


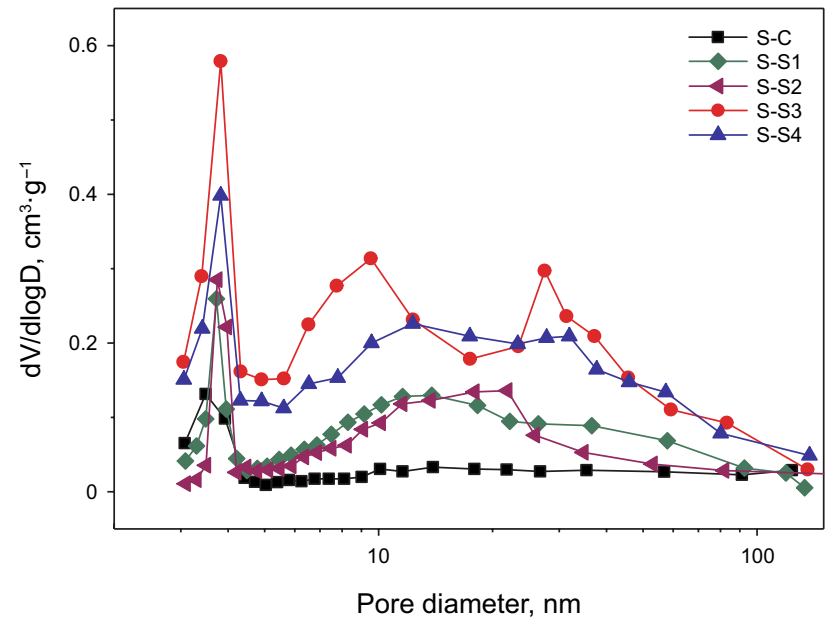

Fig. 5 Pore diameter distributions of $\mathrm{S}-\mathrm{C}$ and $\mathrm{S}-\mathrm{S}_{x}(x=1,2,3$ and 4$)$

Table 1 Texture properties of S-C and S-S $(x=1,2,3$ and 4)

\begin{tabular}{lllll}
\hline Sample & $S_{\text {BET }}, \mathrm{m}^{2} \mathrm{~g}^{-1}$ & $S_{\text {external }}, \mathrm{m}^{2} \mathrm{~g}^{-1}$ & $\begin{array}{l}V_{\text {micropore }}, \\
\mathrm{cm}^{3} \mathrm{~g}^{-1}\end{array}$ & $\begin{array}{l}V_{\text {mesopore }} \\
\mathrm{cm}^{3} \mathrm{~g}^{-1}\end{array}$ \\
\hline $\mathrm{S}-\mathrm{C}$ & 221 & 80 & 0.07 & 0.06 \\
$\mathrm{~S}-\mathrm{S}_{1}$ & 243 & 117 & 0.07 & 0.15 \\
$\mathrm{~S}-\mathrm{S}_{2}$ & 257 & 132 & 0.07 & 0.21 \\
$\mathrm{~S}-\mathrm{S}_{3}$ & 275 & 165 & 0.06 & 0.34 \\
$\mathrm{~S}-\mathrm{S}_{4}$ & 203 & 111 & 0.05 & 0.14 \\
\hline
\end{tabular}

content increases, the ESA of $\mathrm{S}-\mathrm{S}_{x}(x=1,2,3$ and 4) first enhances and then reduces with a maximum of $165 \mathrm{~m}^{2} \mathrm{~g}^{-1}$ at $n(\mathrm{SDBS}) / n\left(\mathrm{SiO}_{2}\right)=0.125\left(\mathrm{~S}-\mathrm{S}_{3}\right)$. This is because the submicron particle size of $\mathrm{S}-\mathrm{S}_{x}(x=1,2$ and 3$)$ follows the order $\mathrm{S}-\mathrm{S}_{1}>\mathrm{S}-\mathrm{S}_{2}>\mathrm{S}-\mathrm{S}_{3}$. The gradual increase in the ESAs of $\mathrm{S}-\mathrm{S}_{1}, \mathrm{~S}-\mathrm{S}_{2}$ and $\mathrm{S}-\mathrm{S}_{3}$ results from their decreased

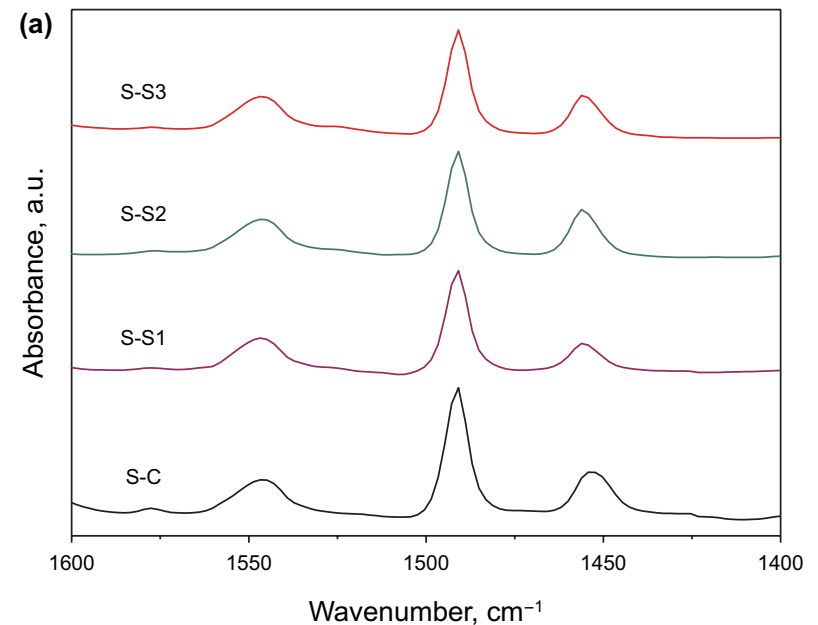

SAPO-11 submicron particle sizes. $\mathrm{S}-\mathrm{S}_{4}$ has a relatively low ESA because of the amorphous materials in $\mathrm{S}_{-} \mathrm{S}_{4}$.

\subsection{Py-IR and 2,6-DMPy-IR}

The Py-IR spectra of S-C, S-S,$S_{1}-S_{2}$ and $S_{-} S_{3}$ at 473 (a) and 573 (b) K are shown in Fig. 6, and they have three adsorption bands from $1400-1600 \mathrm{~cm}^{-1}$. The bands at 1455 and $1545 \mathrm{~cm}^{-1}$ represent the adsorption of pyridine on the $\mathrm{L}$ and B acid centers, respectively (J.A.Z. Pieterse et al. 1999; Zholobenko et al. 2020). The number of total acid centers and moderate and strong acid centers on these samples is determined from the spectra at 473 and $573 \mathrm{~K}$, respectively.

Table 2 shows the number of $\mathrm{L}$ and $\mathrm{B}$ acid centers on $\mathrm{S}-\mathrm{C}, \mathrm{S}-\mathrm{S}_{1}, \mathrm{~S}-\mathrm{S}_{2}$ and $\mathrm{S}-\mathrm{S}_{3}$. All the samples show almost the same number of total BAC and MSBAC. This result indicates that the BAC and MSBAC of these synthesized SAPO11 molecular sieves are hardly affected by the addition of SDBS. The ${ }^{29} \mathrm{Si}$ solid-state nuclear magnetic resonance results of $\mathrm{S}-\mathrm{C}$ and $\mathrm{S}-\mathrm{S}_{3}$ are shown in Fig. S1 and Table S2, which are consistent with the obtained Py-IR results.

The 2,6-DMPy-IR spectra of S-C, S-S, $\mathrm{S}_{1} \mathrm{~S}_{2}$ and $\mathrm{S}-\mathrm{S}_{3}$ at 473 (a) and 573 (b) $\mathrm{K}$ are displayed in Fig. 7, and an adsorption band is observed at $1600-1675 \mathrm{~cm}^{-1}$, which is attributed to the adsorption of 2,6-DMPy-IR on the BAC (Morterra et al. 2001; Lercher and Jentys 2007). 2,6-DMPyIR can only be connected with the BAC located on the ES of SAPO-11 because the diameter of 2,6-DMPy-IR $(6.7 \AA)$ is larger than the pore openings of SAPO-11 (6.3 $\AA$ ) (Thibault-Starzyk et al. 2009). The numbers of total EBAC and external medium and strong BAC (EMSBAC) of S-C, S- $\mathrm{S}_{1}$, $\mathrm{S}-\mathrm{S}_{2}$ and $\mathrm{S}-\mathrm{S}_{3}$ are calculated according to the 2,6-DMPyIR spectra at 473 and $573 \mathrm{~K}$, respectively. The numbers of total EBAC and EMSBAC on S-C, S- $\mathrm{S}_{1}, \mathrm{~S}-\mathrm{S}_{2}$ and $\mathrm{S}-\mathrm{S}_{3}$ are presented in Table 3. The numbers of total EBAC and

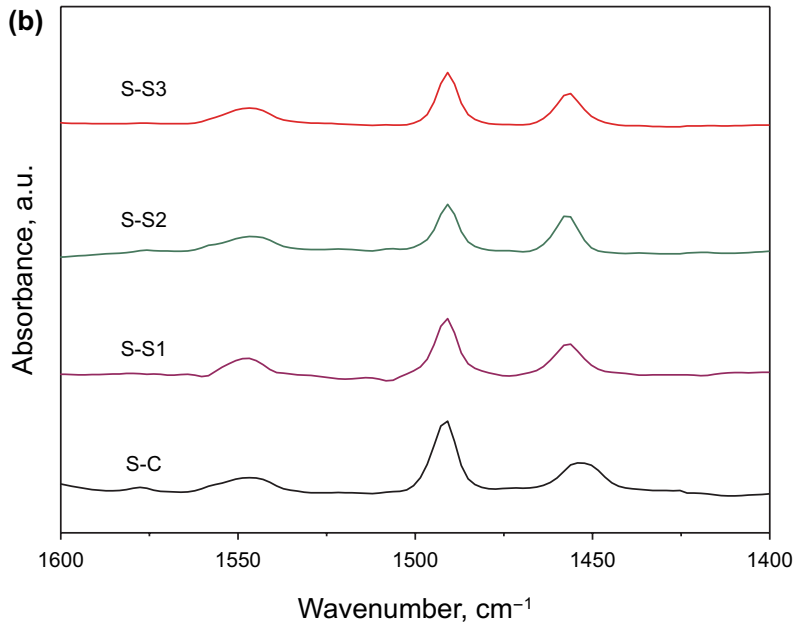

Fig. 6 Py-IR spectra of S-C, S-S, S-S $\mathrm{S}_{2}$ and $\mathrm{S}-\mathrm{S}_{3}$ at $473 \mathrm{~K}$ (a) and $573 \mathrm{~K}(\mathbf{b})$ 
Table 2 Acidities of $\mathrm{S}-\mathrm{C}, \mathrm{S}-\mathrm{S}_{1}, \mathrm{~S}-\mathrm{S}_{2}$ and $\mathrm{S}-\mathrm{S}_{3}$ determined from the Py-IR spectra

\begin{tabular}{llllll}
\hline Sample & \multicolumn{2}{l}{$\begin{array}{l}\text { B acid centers }(\mu \mathrm{mol} \text { Pyri- } \\
\left.\text { dine } \mathrm{g}^{-1}\right)\end{array}$} & & \multicolumn{2}{l}{$\begin{array}{l}\text { L acid centers }(\mu \mathrm{mol} \\
\left.\text { Pyridine } \mathrm{g}^{-1}\right)\end{array}$} \\
\cline { 2 - 3 } \cline { 6 - 6 } \cline { 6 - 6 } & $473 \mathrm{~K}$ & $573 \mathrm{~K}$ & & $473 \mathrm{~K}$ & $573 \mathrm{~K}$ \\
\hline S-C & 72.1 & 31.9 & & 36.9 & 28.2 \\
S-S & 72.5 & 32.7 & & 36.2 & 27.0 \\
S-S & 72.0 & 32.0 & & 36.5 & 24.2 \\
$\mathrm{~S}_{2}-\mathrm{S}_{3}$ & 74.1 & 33.3 & & 35.3 & 24.1 \\
\hline
\end{tabular}

EMSBAC on these samples both follow the order $\mathrm{S}_{-} \mathrm{S}_{3}>$ $\mathrm{S}-\mathrm{S}_{2}>\mathrm{S}-\mathrm{S}_{1}>\mathrm{S}-\mathrm{C}$. This is because SAPO-11, with a high ESA, exposes a large number of EBAC (Guo et al. 2012), and the ESA of $\mathrm{S}-\mathrm{C}, \mathrm{S}-\mathrm{S}_{1}, \mathrm{~S}-\mathrm{S}_{2}$ and $\mathrm{S}-\mathrm{S}_{3}$ gradually increases. $\mathrm{S}-\mathrm{S}_{3}$ has the greatest numbers of EBAC and EMSBAC among these SAPO-11 samples.

\subsection{Catalytic performance}

The results of $n$-nonane hydroisomerization over Pt/S-S $(x=1,2$ and 3$)$ and Pt/S-C at different WHSVs, a v $\left(\mathrm{H}_{2}\right) / \mathrm{v}(n-$ nonane) of 400 , a pressure of $1.5 \mathrm{MPa}$ and a temperature of $613 \mathrm{~K}$ are exhibited in Fig. 8. As the WHSV increases, the $n$-nonane conversions for all catalysts decrease. As the $n$-nonane conversion increases, the selectivity to entire isomers $\left(S_{\mathrm{E}}\right)$ decreases, and the hydrocracking selectivity $\left(S_{\mathrm{H}}\right)$ and the selectivity to di-branched isomers $\left(S_{\mathrm{DB}}\right)$ increase. The conversions of n-nonane at the same WHSV follow the

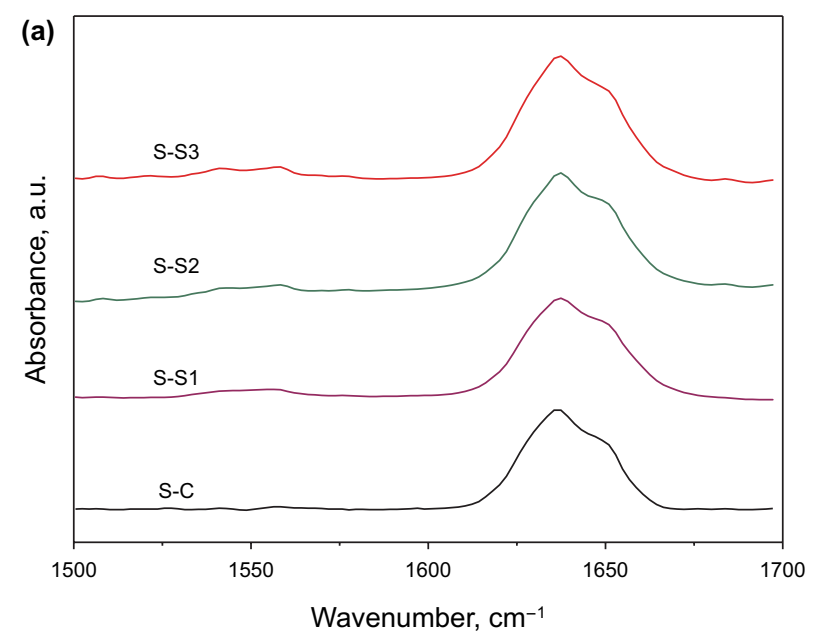

sequence $\mathrm{Pt} / \mathrm{S}-\mathrm{C}<\mathrm{Pt} / \mathrm{S}-\mathrm{S}_{1}<\mathrm{Pt} / \mathrm{S}-\mathrm{S}_{2}<\mathrm{Pt} / \mathrm{S}-\mathrm{S}_{3}$. In addition, $\mathrm{Pt} / \mathrm{S}-\mathrm{S}_{3}$ presents the highest $S_{\mathrm{E}}$ and $S_{\mathrm{DB}}$, and the minimum $S_{\mathrm{H}}$ at the same $n$-nonane conversion among these catalysts.

The product distribution of hydroisomerization of $n$-nonane on these catalysts ( $n$-nonane conversion of approximately $88 \%$ ) is displayed in Table 4 . The main products of $n$-nonane hydroisomerization are 2,4-dimethylheptane (2,4DMC7), 3,4-dimethylheptane (3,4-DMC7), 4-methyloctane (4-MC8), 2,2-dimethylheptane (2,2-DMC7), 4-ethylheptane (4-EC8), 2,3-dimethylheptane (2,3-DMC7), 3-methyloctane (3-MC8), 3,5-dimethylheptane (3,5-DMC7), 2-methyloctane (2-MC8), 2,6-dimethylheptane (2,6-DMC7), 2-methyl3-ethylhexane (2-M-3-EC6) and 2,5-dimethylheptane (2,5DMC7). Pt/S-S 3 presents higher $S_{\mathrm{E}}(83.4 \%)$ and $S_{\mathrm{DB}}(28.1 \%)$ values and lower $S_{\mathrm{H}}(15.7 \%)$ values than $\mathrm{Pt} / \mathrm{S}-\mathrm{S}_{1}(81.7 \%$, $24.7 \%$ and $17.4 \%), \mathrm{Pt} / \mathrm{S}-\mathrm{S}_{2}(82.7 \%, 26.3 \%$ and $16.4 \%)$ and $\mathrm{Pt} / \mathrm{S}-\mathrm{C}(76.5 \%, 22.4 \%$ and $22.6 \%)$ at the $n$-nonane conversion of approximately $88 \%$. Furthermore, $\mathrm{Pt} / \mathrm{S}-\mathrm{S}_{3}$ has the highest $\mathrm{k}$ value and the largest TOF among these catalysts.

Table 3 Acidities of $\mathrm{S}-\mathrm{C}, \mathrm{S}-\mathrm{S}_{1}, \mathrm{~S}-\mathrm{S}_{2}$ and $\mathrm{S}-\mathrm{S}_{3}$ determined from the 2,6-DMPy-IR spectra

\begin{tabular}{llc}
\hline Sample & \multicolumn{2}{c}{ B acidity $\left(\mu \mathrm{mol} 2,6-D M P y-\mathrm{IR} \mathrm{g}^{-1}\right)$} \\
\cline { 2 - 3 } & $473 \mathrm{~K}$ & $573 \mathrm{~K}$ \\
\hline $\mathrm{S}-\mathrm{C}$ & 41.5 & 13.5 \\
$\mathrm{~S}-\mathrm{S}_{1}$ & 46.2 & 15.7 \\
$\mathrm{~S}-\mathrm{S}_{2}$ & 52.5 & 19.2 \\
$\mathrm{~S}-\mathrm{S}_{3}$ & 56.9 & 23.3 \\
\hline
\end{tabular}

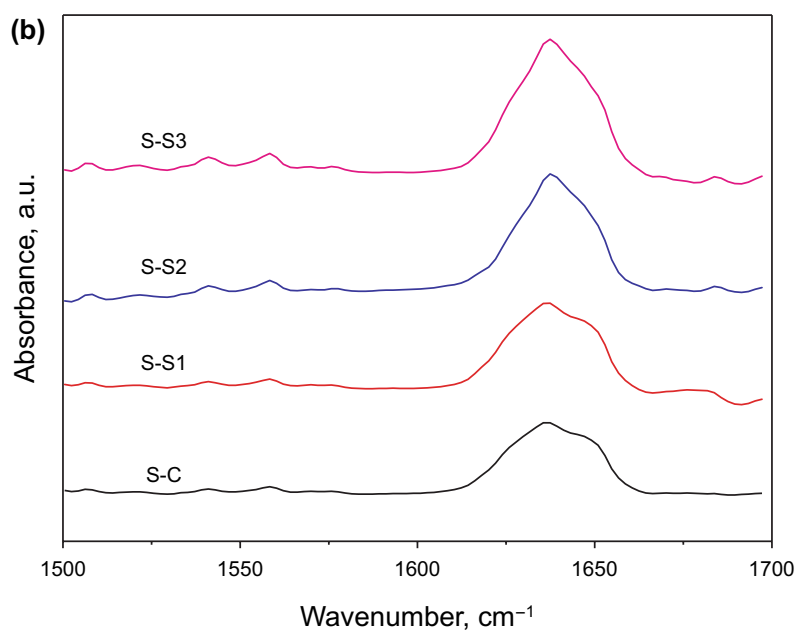

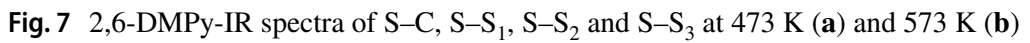



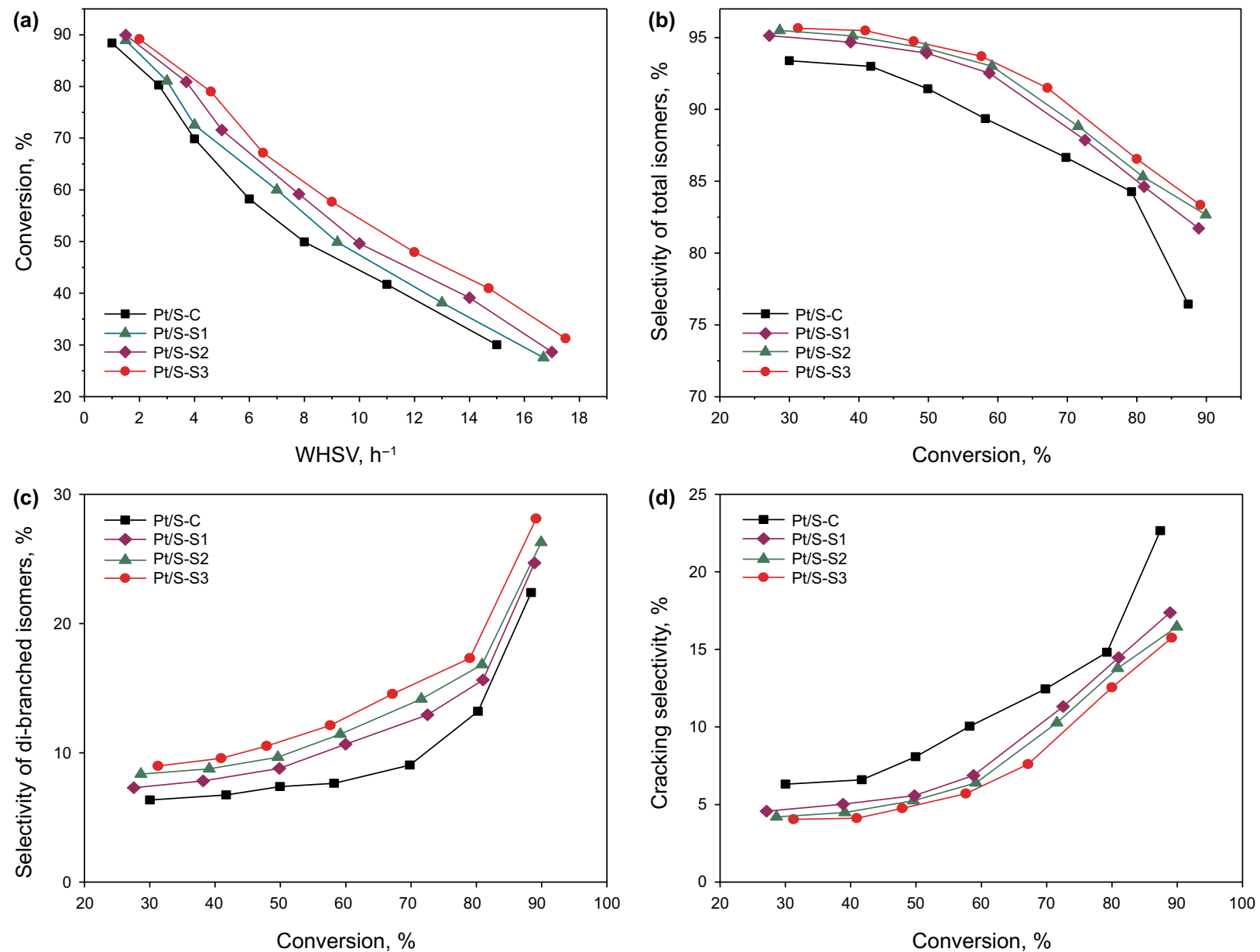

Fig. 8 Conversion versus WHSV (a), selectivity to entire isomers (b), selectivity to di-branched isomers (c) and hydrocracking selectivity (d) versus $n$-nonane conversion for $\mathrm{Pt} / \mathrm{S}-\mathrm{C}, \mathrm{Pt} / \mathrm{S}-\mathrm{S}_{1}, \mathrm{Pt} / \mathrm{S}-\mathrm{S}_{2}$ and $\mathrm{Pt} / \mathrm{S}-\mathrm{S}_{3}$

The explanation of the results of $n$-nonane hydroisomerization on these catalysts is shown as follows. The Pt loadings of these catalysts are $0.5 \mathrm{wt} \%$, and the Pt dispersions for $\mathrm{Pt} / \mathrm{S}-\mathrm{C}, \mathrm{Pt} / \mathrm{S}-\mathrm{S}_{1}, \mathrm{Pt} / \mathrm{S}-\mathrm{S}_{2}$ and $\mathrm{Pt} / \mathrm{S}-\mathrm{S}_{3}$ are $58 \%, 59 \%, 59 \%$ and $60 \%$, respectively. These almost identical Pt dispersions indicate that the pore structure, the ESA and the acidities of the supports chiefly decide the $n$-nonane hydroisomerization performance.

The principles of hydroisomerization of $n$-nonane on Pt/SAPO-11 with different submicron particle sizes are displayed in Fig. 9. The di-branched nonane isomers are unable to be produced inside the pores of SAPO-11 because its diameter (7.1 $\mathrm{A}$ ) (Akhmedov and Al-Khowaiter
2007) is larger than the pore openings of SAPO-11 (6.3 $\mathrm{A})$. According to "pore mouth" theory (Taylor and Petty 1994), di-branched nonane isomers are produced on the EBAC of SAPO-11. $n$-Nonane undergoes the dehydrogenation reaction at the Pt sites to afford an $n$-nonene intermediate. Then, the $n$-nonene intermediate is isomerized at the BAC to afford a mono-branched nonene intermediate. Afterward, the methyl of the intermediate is adsorbed at one pore mouth, and the opposite side of the intermediate is adsorbed at a next pore mouth. The isomerization of the mono-branched nonene intermediate occurs at the BAC to produce a di-branched nonene intermediate. The di-branched isomer is obtained by hydrogenation of the 
Table 4 Results of $n$-nonane hydroisomerization over Pt/S-C, Pt/S$\mathrm{S}_{1}, \mathrm{Pt} / \mathrm{S}-\mathrm{S}_{2}$ and $\mathrm{Pt} / \mathrm{S}-\mathrm{S}_{3}$

\begin{tabular}{lllll}
\hline & $\mathrm{Pt} / \mathrm{S}-\mathrm{S}_{3}$ & $\mathrm{Pt} / \mathrm{S}-\mathrm{S}_{2}$ & $\mathrm{Pt} / \mathrm{S}-\mathrm{S}_{1}$ & $\mathrm{Pt} / \mathrm{S}-\mathrm{C}$ \\
\hline$k^{\mathrm{a}}\left(10^{-6} \mathrm{~mol} \mathrm{~g}^{-1} \mathrm{~s}^{-1}\right)$ & 15 & 13 & 12 & 10 \\
$\mathrm{TOF}^{\mathrm{a}}\left(10^{-2} \mathrm{~s}^{-1}\right)$ & 35.7 & 33.0 & 31.1 & 27.7 \\
$S_{\mathrm{E}}(\%)$ & 83.4 & 82.7 & 81.7 & 76.5 \\
$S_{\mathrm{DB}}(\%)$ & 28.1 & 26.3 & 24.7 & 22.4 \\
$P S^{\mathrm{b}}$ & & & & \\
2-MC8 & 5.2 & 5.5 & 5.9 & 5.0 \\
3-MC8 & 21.8 & 22.4 & 21.6 & 20.9 \\
4-MC8 & 27.0 & 27.3 & 28.4 & 27.2 \\
4-EC7 & 1.3 & 1.2 & 1.1 & 1.0 \\
2,2-DMC7 & 0.7 & 0.6 & 0.6 & 0.6 \\
2,3-DMC7 & 1.2 & 1.0 & 0.9 & 0.6 \\
2,4-DMC7 & 4.1 & 3.8 & 3.2 & 2.9 \\
2,5-DMC7 & 12.1 & 11.6 & 11.1 & 10.0 \\
2,6-DMC7 & 5.4 & 5.1 & 4.9 & 4.7 \\
3,4-DMC7 & 2.9 & 2.7 & 2.6 & 2.4 \\
3,5-DMC7 & 0.8 & 0.7 & 0.7 & 0.7 \\
2-M-3-EC6 & 0.9 & 0.8 & 0.7 & 0.5 \\
Others & 0.9 & 0.9 & 0.9 & 0.9 \\
$S_{\mathrm{H}}$ (\%) & 15.7 & 16.4 & 17.4 & 22.6 \\
\hline
\end{tabular}

${ }^{a}$ Obtained at $613 \mathrm{~K}, 1.5 \mathrm{MPa}$, a $v\left(\mathrm{H}_{2}\right) / v(n$-nonane) of 400 and $n$-nonane conversion of ca. $20 \%$

${ }^{\mathrm{b}} \mathrm{PS}$ represents products selectivity

di-branched nonene intermediate at the Pt sites. As shown in Fig. 9, SAPO-11 with large submicron particles has a low ESA and a small number of EBAC, which provides fewer active sites at the pore mouths, thereby yielding a small number of di-branched nonane isomers (Fig. 9a); in contrast, SAPO-11, with small submicron particles, has a high ESA and a large number of EBAC, which offers more active sites at the pore mouths, thereby generating more di-branched nonane isomers (Fig. 9b).

Compared with the microporous molecular sieve, the reactant molecules are more easily adsorbed on the BAC of the hierarchical molecular sieve with a high ESA (Zhou et al. 2014), and thus, Pt/SAPO-11 with a high ESA and a large number of EBAC exhibits high $n$-nonane hydroisomerization activity. Pt/S-C displays the lowest conversion of $n$-nonane, $S_{\mathrm{DB}}$ and $S_{\mathrm{E}}$ and the highest $S_{\mathrm{H}}$ of all the catalysts. It is because S-C has the lowest ESA (Table 1) and the smallest number of EMSBAC (Table 3) among these samples, thus offering the fewest active sites at the pore mouths for $n$-nonane hydroisomerization. Additionally, $\mathrm{S}-\mathrm{C}$ has large submicron particles, which makes the $n$-nonane branched isomers difficult to diffuse, thereby promoting hydrocracking reactions.

Compared with $\mathrm{Pt} / \mathrm{S}-\mathrm{C}, \mathrm{Pt} / \mathrm{S}-\mathrm{S}_{x}(x=1,2$ and 3$)$ shows a higher $n$-nonane conversion at the same WHSV and displays higher $S_{\mathrm{E}}$ and $S_{\mathrm{DB}}$ values and a lower $S_{\mathrm{H}}$ at the same $n$-nonane conversion. This is because $\mathrm{S}-\mathrm{S}_{x}(x=1,2$ and 3) possesses a higher ESA (Table 1) and a larger number of EMSBAC (Table 3) than $\mathrm{S}-\mathrm{C}$, thus providing more active sites at the pore mouths for $n$-nonane hydroisomerization. Furthermore, $\mathrm{S}-\mathrm{S}_{x}(x=1,2$ and 3$)$ has smaller submicron particles than $\mathrm{S}-\mathrm{C}$, making diffusion of the $n$-nonane branched isomers easy and reducing the hydrocracking reactions.

The $n$-nonane conversions for $\mathrm{Pt} / \mathrm{S}-\mathrm{S}_{x}(x=1,2$ and 3) follow the order Pt/S-S $\mathrm{S}_{1}<\mathrm{Pt} / \mathrm{S}-\mathrm{S}_{2}<\mathrm{Pt} / \mathrm{S}-\mathrm{S}_{3}$ at the same WHSV. In addition, the $S_{\mathrm{E}}$ and $S_{\mathrm{DB}}$ values for $\mathrm{Pt} / \mathrm{S}-\mathrm{S}_{x}(x=1$, 2 and 3) sequentially increase, and the $S_{\mathrm{H}}$ values gradually decrease at the same $n$-nonane conversion. This is because the ESA (Table 1) and the number of EMSBAC (Table 3) of $\mathrm{S}_{-} \mathrm{S}_{x}(x=1,2$ and 3$)$ follow the order $\mathrm{S}-\mathrm{S}_{1}<\mathrm{S}-\mathrm{S}_{2}<\mathrm{S}-\mathrm{S}_{3}$, and SAPO-11, with a higher ESA and a larger number of EMSBAC, has more active sites at the pore mouths for $n$-nonane hydroisomerization. Furthermore, the submicron particle sizes of $\mathrm{S}-\mathrm{S}_{x}(x=1,2$ and 3$)$ are in sequence $\mathrm{S}-\mathrm{S}_{1}>$ $\mathrm{S}_{-} \mathrm{S}_{2}>\mathrm{S}-\mathrm{S}_{3}$ (Fig. 2), and SAPO-11, with small submicron particles, provides a short residence time for $n$-nonane branched isomers and their intermediates and promotes their diffusion, thereby reducing the hydrocracking reactions. Consequently, $\mathrm{Pt} / \mathrm{S}-\mathrm{S}_{3}$ shows the highest $S_{\mathrm{E}}(83.4 \%)$, the highest $S_{\mathrm{DB}}(28.1 \%)$ and the lowest $S_{\mathrm{H}}(15.7 \%)$ among these catalysts. 
(a)

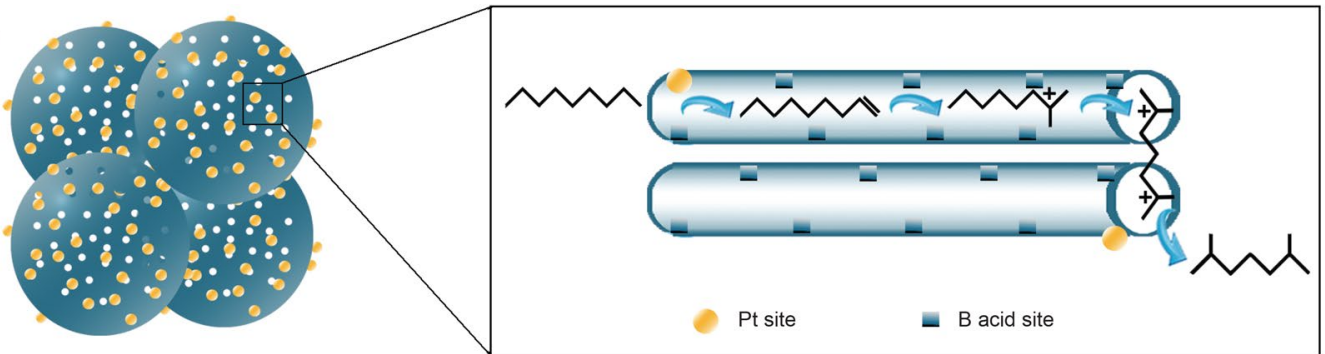

Pt/SAPO-11 with large submicron particles

(b)

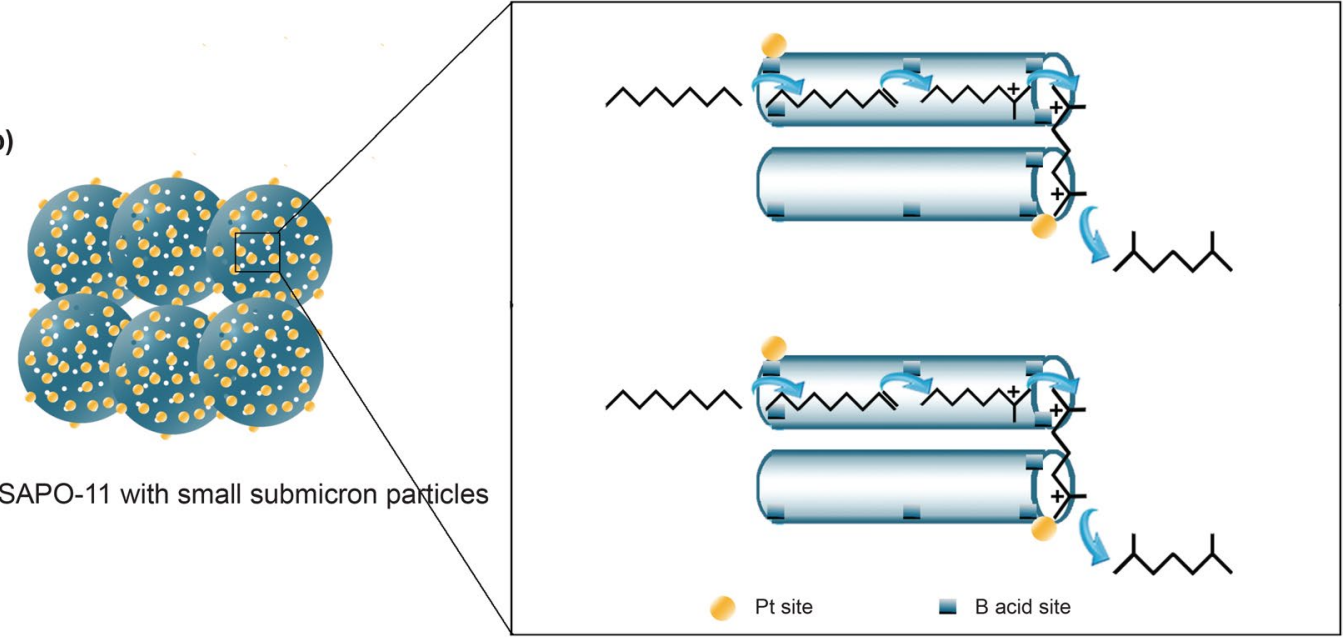

Fig. 9 Principles of the generation of di-branched n-nonane isomers over Pt/SPAO-11 with large submicron particles (a) and small submicron particles (b)

\section{Conclusions}

To convert the low-octane $n$-alkanes to their high-octane di-branched isomers, a variety of hierarchical SAPO-11 are synthesized by adding different amounts of the anionic surfactant (sodium dodecylbenzene sulfonate, SDBS), and their corresponding catalysts are applied in $n$-nonane hydroisomerization. In the case of $n(\mathrm{SDBS}) / n\left(\mathrm{SiO}_{2}\right)$ is less than or equal to 0.125 , as the SDBS content increases, the submicron particle sizes of the obtained hierarchical SAPO-11 gradually decrease, and the ESA increase. Compared with conventional SAPO-11, these hierarchical SAPO-11 molecular sieves have smaller submicron particles and larger ESA. In the case of $n(\mathrm{SDBS}) / n\left(\mathrm{SiO}_{2}\right)$ is greater than 0.125 , as the SDBS content increases $\left(n(\mathrm{SDBS}) / n\left(\mathrm{SiO}_{2}\right)=0.25\right)$, the synthesized SAPO-11 molecular sieve develops amorphous materials, thereby decreasing its ESA; with a further increase in the SDBS content $\left(n(\mathrm{SDBS}) / n\left(\mathrm{SiO}_{2}\right)=0.5\right)$, the products are all amorphous materials. At $n(\mathrm{SDBS}) / n\left(\mathrm{SiO}_{2}\right)=0.125$, the synthesized hierarchical SAPO-11 molecular sieve $\left(\mathrm{S}-\mathrm{S}_{3}\right)$ possesses the smallest submicron particles $(110 \mathrm{~nm})$, the largest ESA $\left(165 \mathrm{~m}^{2} \mathrm{~g}^{-1}\right)$ and the maximum number of EMSBAC $\left(23.3 \mu \mathrm{mol} 2,6-\mathrm{DMPy}-\mathrm{IR}^{-1}\right)$ among these SAPO-11 samples. $\mathrm{Pt} / \mathrm{S}-\mathrm{S}_{3}$ displays the best selectivity to entire isomers $(83.4 \%)$, the best selectivity to di-branched isomers $(28.1 \%)$ and the minimum hydrocracking selectivity (15.7\%) of all the catalysts in $n$-nonane hydroisomerization. 
Supplementary Information The online version contains supplementary material available at https://doi.org/10.1007/s12182-021-00544-3.

Acknowledgments The authors gratefully acknowledge the financial support of the National Natural Science Foundation of China (Grant No. 21978323).

Open Access This article is licensed under a Creative Commons Attribution 4.0 International License, which permits use, sharing, adaptation, distribution and reproduction in any medium or format, as long as you give appropriate credit to the original author(s) and the source, provide a link to the Creative Commons licence, and indicate if changes were made. The images or other third party material in this article are included in the article's Creative Commons licence, unless indicated otherwise in a credit line to the material. If material is not included in the article's Creative Commons licence and your intended use is not permitted by statutory regulation or exceeds the permitted use, you will need to obtain permission directly from the copyright holder. To view a copy of this licence, visit http://creativecommons.org/licenses/by/4.0/.

\section{References}

Akhmedov VM, Al-Khowaiter SH. Recent advances and future aspects in the selective isomerization of high n-alkanes. Catal Rev. 2007;49(1):133-9. https://doi.org/10.1080/01614940601128427.

Ahn CK, Park D, Woo SH, Park JM. Removal of cationic heavy metal from aqueous solution by activated carbon impregnated with anionic surfactants. J Hazard Mater. 2009;164(2):1130-6. https://doi. org/10.1016/J.JHAZMAT.2008.09.036.

Belinskaya NS, Frantsina EV, Ivanchina ED. Unsteady-state mathematical model of diesel fuels catalytic dewaxing process. Catal Today. 2019;329:214-20. https://doi.org/10.1016/J.CATTO D.2018.10.041.

Chen Z, Dong Y, Jiang S, Song W, Lai W, Yi X, et al. Low-temperature synthesis of hierarchical architectures of SAPO-11 zeolite as a good hydroisomerization support. J Mater Sci. 2017;52(8):4460 71. https://doi.org/10.1007/S10853-016-0692-Z.

Chi K, Zhao Z, Tian Z, Hu S, Yan L, Li T, et al. Hydroisomerization performance of platinum supported on ZSM-22/ZSM-23 intergrowth zeolite catalyst. Petrol Sci. 2013;10(2):242-50. https:// doi.org/10.1007/S12182-013-0273-6.

Chica A, Corma A. Hydroisomerization of pentane, hexane, and heptane for improving the octane number of gasoline. J Catal. 1999;187(1):167-76. https://doi.org/10.1006/jcat.1999.2601.

Che S, Garcia-Bennett AE, Yokoi T, Sakamoto K, Kunieda H, Terasaki $\mathrm{O}$, et al. A novel anionic surfactant templating route for synthesizing mesoporous silica with unique structure. Nat Mater. 2003;2(12):801-5. https://doi.org/10.1038/NMAT1022.

Campelo JM, Lafont F, Marinas JM. Hydroisomerization and hydrocracking of $n$-heptane on $\mathrm{Pt} / \mathrm{SAPO}-5$ and Pt/SAPO-11 catalysts. J Catal. 1995;156:11-8. https://doi.org/10.1006/JCAT.1995.1226.

Cundy CS, Cox PA. The hydrothermal synthesis of zeolites: Precursors, intermediates and reaction mechanism. Micropor Mesopor Mat. 2005;82(1):1-78. https://doi.org/10.1016/j.micro meso.2005.02.016.

Chen N, Gong S, Shirai H, Watanabe T, Qian EW. Effects of Si/Al ratio and $\mathrm{Pt}$ loading on $\mathrm{Pt} / \mathrm{SAPO}-11$ catalysts in hydroconversion of Jatropha oil. Appl Catal A: Gen. 2013;466:105-15. https://doi. org/10.1016/J.APCATA.2013.06.034.

Danilina N, Krumeich F, van Bokhoven JA. Hierarchical SAPO-5 catalysts active in acid-catalyzed reactions. J Catal. 2010;272(1):3743. https://doi.org/10.1016/j.jcat.2010.03.014.
Emeis CA. Determination of integrated molar extinction coefficients for infrared absorption bands of pyridine adsorbed on solid acid catalysts. J Catal. 1993;141:347-54. https://doi.org/10.1006/ JCAT.1993.1145.

Fan Y, Xiao H, Shi G, Liu H, Bao X. Alkylphosphonic acid- and small amine-templated synthesis of hierarchical silicoaluminophosphate molecular sieves with high isomerization selectivity to di-branched paraffins. J Catal. 2012;285(1):251-9. https://doi. org/10.1016/j.jcat.2011.09.037.

Güleç F, Sher F, Karaduman A. Catalytic performance of $\mathrm{Cu}-$ and $\mathrm{Zr}$-modified beta zeolite catalysts in the methylation of 2-methylnaphthalene. Pet Sci. 2019;16(1):161-72. https://doi.org/10.1007/ S12182-018-0278-2.

Gomes LC, Rosas DdO, Chistone RC, Zotin FMZ, Araujo LRRd, Zotin JL. Hydroisomerization of n-hexadecane using Pt/aluminaBeta zeolite catalysts for producing renewable diesel with low pour point. Fuel. 2017;209:521-8. https://doi.org/10.1016/J. FUEL.2017.08.011.

Guo L, Fan Y, Bao X, Shi G, Liu H. Two-stage surfactant-assisted crystallization for enhancing SAPO-11 acidity to improve n-octane di-branched isomerization. J Catal. 2013;301:162-73. https://doi. org/10.1016/J.JCAT.2013.02.001.

Guo L, Bao X, Fan Y, Shi G, Liu H, Bai D. Impact of cationic surfactant chain length during SAPO-11 molecular sieve synthesis on structure, acidity, and n-octane isomerization to di-methyl hexanes. J Catal. 2012;294:161-70. https://doi.org/10.1016/J. JCAT.2012.07.016.

Höchtl M, Jentys A, Vinek H. Alkane conversion over Pd/SAPO molecular sieves: influence of acidity, metal concentration and structure. Catal Today. 2001;65(2):171-7. https://doi.org/10.1016/ S0920-5861(00)00581-2.

Han Z, Ma Z, Wang C-B, He C-Y, Ke M, Jiang Q-Z, et al. Effect of modified carrier fluoride on the performance of Ni-Mo/ $/ \mathrm{Al}_{2} \mathrm{O}_{3}$ catalyst for thioetherification. Pet Sci. 2020. https://doi.org/10.1007/ S12182-020-00439-9.

Huang T, Peng Q, Shi W, Xu J, Fan Y. An anionic surfactant-assisted equilibrium adsorption method to prepare highly dispersed $\mathrm{Fe}$ promoted $\mathrm{Ni} / \mathrm{Al}_{2} \mathrm{O}_{3}$ catalysts for highly selective mercaptan removal. Appl Catal B: Environ. 2018;230:154-64. https://doi. org/10.1016/J.APCATB.2018.02.053.

Hait SK, Majhi PR, Blume A, Moulik SP. A critical assessment of micellization of sodium dodecyl benzene sulfonate (SDBS) and its interaction with poly(vinyl pyrrolidone) and hydrophobically modified polymers, JR 400 and LM 200. J Phys Chem B. 2003;107(15):3650-8. https://doi.org/10.1021/jp027379r.

Ikuno T, Chaikittisilp W, Liu Z, Iida T, Yanaba Y, Yoshikawa T, et al. Structure-directing behaviors of tetraethylammonium cations toward zeolite beta revealed by the evolution of aluminosilicate species formed during the crystallization process. JACS. 2015;137(45):14533-44. https://doi.org/10.1021/JACS.5B11046.

Jin C, Ma B, Zhang X, Ling F, Zhang Z, Qin B. Catalytic performance of $\mathrm{Pt} / \mathrm{HY}-\beta$ in $n$-octane hydroisomerization. Pet Sci. 2009;6(3):299-305. https://doi.org/10.1007/S12182-009-0048-2.

Jaroszewska K, Fedyna M, Trawczyński J. Hydroisomerization of long-chain n-alkanes over Pt/A1SBA-15+zeolite bimodal catalysts. Appl Catal B: Environ. 2019;255:117756. https://doi. org/10.1016/j.apcatb.2019.117756.

Jahn E, Müller D, Becker K. Characterization of the local environment of $\mathrm{Si}$ atoms incorporated into $\mathrm{AlPO}_{4}-11$ by means of ${ }^{27} \mathrm{Al},{ }^{31} \mathrm{P}$ and ${ }^{29}$ Si MAS N.M.R. spectroscopy. Zeolites. 1990;10(3):151-6. https ://doi.org/10.1016/0144-2449(90)90038-S.

Kim MY, Lee K, Choi M. Cooperative effects of secondary mesoporosity and acid site location in Pt/SAPO-11 on n-dodecane hydroisomerization selectivity. J Catal. 2014;319:232-8. https://doi. org/10.1016/J.JCAT.2014.09.001. 
Kuchar PJ, Bricker JC, Reno ME, Haizmann RS. Paraffin isomerization innovations. Fuel Process Technol. 1993;35:183-200. https://doi. org/10.1016/0378-3820(93)90091-H.

Liu Z, Liu L, Song H, Wang C, Xing W, Komarneni S, et al. Hierarchical SAPO-11 preparation in the presence of glucose. Mater Lett. 2015;154:116-9. https://doi.org/10.1016/J.MATLE T.2015.04.067.

Lyu Y, Yu Z, Yang Y, Liu Y, Zhao X, Liu X, et al. Metal and acid sites instantaneously prepared over Ni/SAPO-11 bifunctional catalyst. J Catal. 2019;374:208-16. https://doi.org/10.1016/j. jcat.2019.04.031.

Li B, Tian P, Qi Y, Zhang L, Xu S, Su X, et al. Study of crystallization process of SAPO-11 molecular sieve. Chin J Catal. 2013;34(3):593-603. https://doi.org/10.1016/S1872 $-2067(12) 60542-7$.

Lercher JA, Jentys A. Infrared and raman spectroscopy for characterizing zeolites. Stud Surf Sci Catal. 2007;168:435-76. https://doi. org/10.1016/S0167-2991(07)80801-9.

Myatt GJ, Budd PM, Price C, Hollway F, Carr SW. The influence of surfactants and water-soluble polymers on the crystallization of zeolite NaA. Zeolites. 1994;14(3):190-7. https://doi. org/10.1016/0144-2449(94)90154-6.

Morterra C, Cerrato G, Meligrana G. Revisiting the use of 2,6-dimethylpyridine adsorption as a probe for the acidic properties of metal oxides. Langmuir. 2001;17(22):7053-60. https://doi.org/10.1021/ LA010707E

Pieterse JAZ, Veefkind-Reyes S, Seshan K, Domokos L, Lercher JA. On the accessibility of acid sites in ferrierite for pyridine. J Catal. 1999;187:518-20. https://doi.org/10.1006/JCAT.1999.2629.

Qin B, Zhang X, Zhang Z, Ling F, Sun W. Synthesis, characterization and catalytic properties of Y- $\beta$ zeolite composites. Pet Sci. 2011;8(2):224-8. https://doi.org/10.1007/S12182-011-0139-8.

Song C, Feng Y, Ma L. Characterization and hydroisomerization performance of SAPO-11 molecular sieves synthesized by dry gel conversion. Micropor Mesopor Mat. 2012;147(1):205-11. https ://doi.org/10.1016/J.MICROMESO.2011.06.019.

Sheng N, Xu H, Liu X, Chu Y, Han S, Meng X, et al. Self-formation of hierarchical SAPO-11 molecular sieves as an efficient hydroisomerization support. Catal Today. 2019. https://doi. org/10.1016/J.CATTOD.2019.06.069.

Sakthivel A, Iida A, Komura K, Sugi Y, Chary KVR. Nanosized $\beta$-zeolites with tunable particle sizes: Synthesis by the dry gel conversion (DGC) method in the presence of surfactants, characterization and catalytic properties. Micropor Mesopor Mat. 2009;119(1):322-30. https://doi.org/10.1016/J.MICRO MESO.2008.10.034.

Sun Y, Ma T, Zhang L, Song Y, Shang Y, Zhai Y, et al. The influence of zoned Al distribution of ZSM-5 zeolite on the reactivity of hexane cracking. Mol Catal. 2020;484. https://doi.org/10.1016/J. MCAT.2020.110770.
Taylor RJ, Petty RH. Selective hydroisomerization of long chain normal paraffins. Appl Catal A: Gen. 1994;119(1):121-38. https:// doi.org/10.1016/0926-860X(94)85029-1.

Thibault-Starzyk F, Stan I, Abelló S, Bonilla A, Thomas K, Fernandez $\mathrm{C}$, et al. Quantification of enhanced acid site accessibility in hierarchical zeolites-The accessibility index. J Catal. 2009;264(1):114. https://doi.org/10.1016/J.JCAT.2009.03.006.

Wen C, Han S, Xu J, Fan Y. A novel route to synthesize SAPO-11 molecular sieves with a high external surface area in the presence of ethylene glycol and supercritical carbon dioxide for 1-octene hydroisomerization to dimethylhexanes. J Catal. 2017;356:100 10. https://doi.org/10.1016/J.JCAT.2017.05.021.

Wen C, Wang X, Xu J, Fan Y. Hierarchical SAPO-11 molecular sieve-based catalysts for enhancing the double-branched hydroisomerization of alkanes. Fuel. 2019;255:115821. https://doi. org/10.1016/J.FUEL.2019.115821.

Wang L, Yang W, Xin C, Ling F, Sun W, Fang X, et al. Synthesis of nano-zeolite IM- 5 by hydrothermal method with the aid of PEG and CTAB. Mater Lett. 2012;69:16-9. https://doi.org/10.1016/j. matlet.2011.11.073.

Yang L, Wang W, Song X, Bai X, Feng Z, Liu T, et al. The hydroisomerization of $n$-decane over Pd/SAPO-11 bifunctional catalysts: The effects of templates on characteristics and catalytic performances. Fuel Process Technol. 2019;190:13-20. https:// doi.org/10.1016/J.FUPROC.2019.02.027.

Yang L, Li H, Fu Jy, Li M, Miao C, Wang Z, et al. Synthesis of a novel nano-rod-shaped hierarchical silicoaluminophosphate SAPO-11 molecular sieve with enhanced hydroisomerization of oleic acid to iso-alkanes. RSC Adv. 2019b;9(59):34457-64. https://doi. org/10.1039/C9RA06117G.

Zhang F, Liu Y, Sun Q, Dai Z, Gies H, Wu Q, et al. Design and preparation of efficient hydroisomerization catalysts by the formation of stable SAPO-11 molecular sieve nanosheets with 10-20 nm thickness and partially blocked acidic sites. Chem Commun. 2017;53(36):4942-5. https://doi.org/10.1039/C7CC01519D.

Zhao S, Li M, Chu Y, Chen J. Hydroconversion of methyl laurate as a model compound to hydrocarbons on bifunctional $\mathrm{Ni}_{2} \mathrm{P} / \mathrm{SAPO}-11$ : Simultaneous comparison with the performance of Ni/SAPO-11. Energ Fuel. 2014;28(11):7122-32. https://doi.org/10.1021/EF501 $723 \mathrm{P}$.

Zholobenko V, Freitas C, Jendrlin M, Bazin P, Travert A, Thibault-Starzyk F. Probing the acid sites of zeolites with pyridine: Quantitative AGIR measurements of the molar absorption coefficients. J Catal. 2020;385:52-60. https://doi.org/10.1016/J. JCAT.2020.03.003.

Zhou J, Liu Z, Wang Y, Gao H, Li L, Yang W, et al. Enhanced accessibility and utilization efficiency of acid sites in hierarchical MFI zeolite catalyst for effective diffusivity improvement. RSC Adv. 2014;4(82):43752-5. https://doi.org/10.1039/C4RA03986F. 